\title{
Wayfinding Signage Considerations in International Airports
}

\begin{abstract}
Airports are complex spaces that exist primarily for the purpose of allowing significant numbers of people to fly from and into, a specific location. In these spaces, wayfinding is an important process, given that these people need to be moved in a time effective and safe manner, to various locations within the airport. In addition to the use of space, human help, and electronic technologies, static signage is an important tool in guiding people in airports. In this study I focus on static signage as a wayfinding tool in airports and I report on the findings from three wayfinding audits that this author did in three UK international airports in the last year.
\end{abstract}

Keywords: wayfinding, signage, airport wayfinding, human factors

\section{Introduction}

Trying to guide users to and through an airport is a particularly complex activity, especially around some of the large international airports, some of which might be thought of as mini-cities. In 2015, for example, over 100 million passengers flew in or out of Hartsfield-Jackson Atlanta International Airport in the U.S. (ACI, 2016), whilst in the UK, almost 75 million passengers used London Heathrow (ibid). It is not only though passenger who must be guided through airports, but also staff, airline crew (many of whom may be new to the airport), service providers, delivery drivers and so on. Moreover, users from many countries and cultures with varying mother tongues, and of varying abilities need to navigate these spaces. Signage in these airports, for example, needs to be legible for those with a range of visual abilities including those who are visually impaired. Indeed, travellers who suffer from some form of vision impairment, "have a condition that affects the function of their bodies but it is the disabling nature of socially constructed barriers that transforms them into a person with disability" (Small et al, 2012: 942). In this respect, a signage system that is not designed effectively to cater to those with a disability such as a sight problems, further alienates such passengers. Gottdiener (2000: 77) perhaps perfectly highlights the need for a good signage system, commenting that "inadequate sign systems result in passenger delays, perhaps missed planes which back passengers up; increased cost of travel; and the need for more personnel to help in a disorientating airport".

Planning a signage system in an airport is a complex and difficult practice, and this is further complicated by the way in which wayfinding is also a "heuristic" activity (Symonds et al, 2017: 4.3). Likewise, having checked-in and with no rush to navigate to and through the security areas, a passenger might look for a restroom (toilet), a shop to buy a gift, or a restaurant to find a bite to eat. Signage thus needs not only to guide passengers through and between the key areas of an airport, but needs to be designed such that users can also find their way for micro processes within the overall macro route. The meshwork concept (Ingold, 2011; Symonds et al, 2017) is useful in expressing these processes that wayfinding signage needs to accommodate, the meshwork much like a fishing net of divergent paths that meet at certain points (locations where multiple people's bodies meet and cross and move past and by each other). The meshwork represents a set of routes that evolve and are "lived" (Ingold, 2011: 151) rather than being static paths and routes. An effective signage system thus needs to guide people on direct 
Wayfinding Signage Considerations in International Airports

Symonds, $\mathrm{P}$.

Interdisciplinary Journal of Signage and Wayfinding; Volume 1; Issue 2

paths but also to provide for these heuristic wayfinding needs that clearly exist as we move through airports. In most airports, there are four key areas in respect of wayfinding and these are the need to: i) find the airport itself and parking or main arrival points, ii) find the check-in/terminal, iii) navigate through airport and through security, and iv) to the departure gate.

Before proceeding to explain the methodology and then the findings, it is first worth providing a definition of wayfinding. The concept of wayfinding has existed for over a century but was first used as a one word term by Lynch (1960). Since Lynch, a number of definitions have been used in wayfinding literature but the one I use in this paper is from Symonds et al (2017: 4.12) who classify wayfinding as "the cognitive, social and corporeal process and experience of locating, following or discovering a route through and to a given space". Even though wayfinding can be a largely sociocultural process through acts such as people asking, in this paper, I focus on physical signage, drawing on the experiences from auditing three UK airports. I avoid too much focus, in this specific paper, on the design of space and other non-signage wayfinding techniques, in order to focus on physical signage. In the section that follows, the methodology used is explained.

\section{Methodology}

In 2016, as a consultant whilst completing a $\mathrm{PhD}$ in wayfinding, I carried out wayfinding audits for three U.K airports and these were Birmingham International (BHX), Cardiff International (CWL) and London Gatwick (LGW). A total of six visits were made to the airports and permission was given for photographs to be taken and feedback was provided to each airport. No passengers were interviewed on these specific audits.

The findings in this paper are qualitative in nature, justified in that the audits and findings provide an "exploratory" (Silverman, 2013) form of research and on which quantitative research could be based on in the future, if deemed necessary. Qualitative research of this type provides a useful way of discovering underlying issues (Lo Iacono et al, 2016: 2.2) that might not otherwise be discovered in quantitative research. In the section that follows, some of the main issues and solutions in respect of signage are discussed.

\section{Findings and Discussion}

\section{Introduction to the Complexities of Signage and Stakeholders}

Before explaining the various types of signage and related issues, it is worth briefly drawing on Bourdieu's (1977) theory of practice in order to portray the complexities of signage in airports. Bourdieu's concept of field, applied to a given space or environment, allows us to see such space as a social (and not just physical) field with the competing forces (constituted by social actors) acting within and upon that space. Without delving too deeply in this paper into the theory, and various forms of capital and habitus that influence "the field", Bourdieu's comparison of social actors competing in a social field to increase their capital, to players competing in a sport field, help us visualise the way in which various stakeholders shape the process of wayfinding in airports. Airports, when planning a signage system, are influenced by numerous stakeholders in the practice, and these stakeholders all help to shape and ultimately guide the signage design process. These stakeholders include: 
Wayfinding Signage Considerations in International Airports

Symonds, $\mathrm{P}$.

Interdisciplinary Journal of Signage and Wayfinding; Volume 1; Issue 2

- Institutions: such as the government and hence the need to provide regulatory signage and, as it will be discussed below, multi-language signage aimed to push governmental decisions over the protection of a local language.

- Commercial outlets: who want to make their store fronts or service visible.

- Service providers: such as limousine and taxi-cab drivers who need to be able to find their way (not easy in an airport such as JFK in New York, U.S.)

- Passengers: who need to be able to find their way not only to the airport, but through it and this needs to include for small processes such as finding the special assistance desk. Connecting passengers also need to be considered and time is often a precious resource for these passengers.

- Airport owners: different rules exist in each country, regards airport ownership. In the Unites States, for example, airports tend to be state owned whereas airports in the UK are independent ventures and this has a direct impact on the commercialisation of an airport and, in turn, it impacts on the commercial signage in the UK airports.

\section{Signage Types}

The signage, in the three airports studied, can be broken down into five distinct types and these are i) directional, ii) identifying, iii) informational, iv) regulatory and v) commercial. Certain signs inevitably fit into two or more of these categories but the key point to understand is the various forms of signage required to fully accommodate a positive user experience (UX) and to keep users safe, in an airport environment.

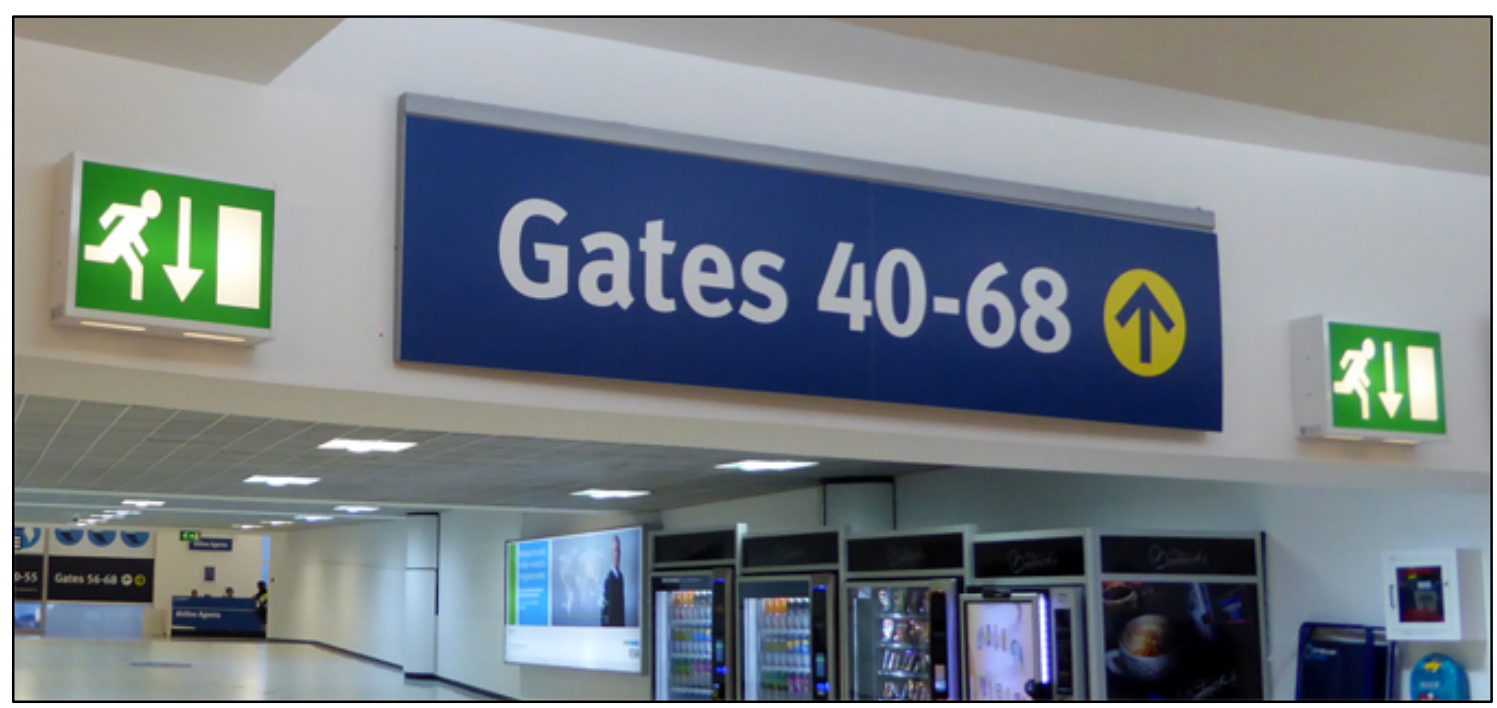

Figure 1 - Example of Directional signage 
Wayfinding Signage Considerations in International Airports

Symonds, $\mathrm{P}$.

Interdisciplinary Journal of Signage and Wayfinding; Volume 1; Issue 2

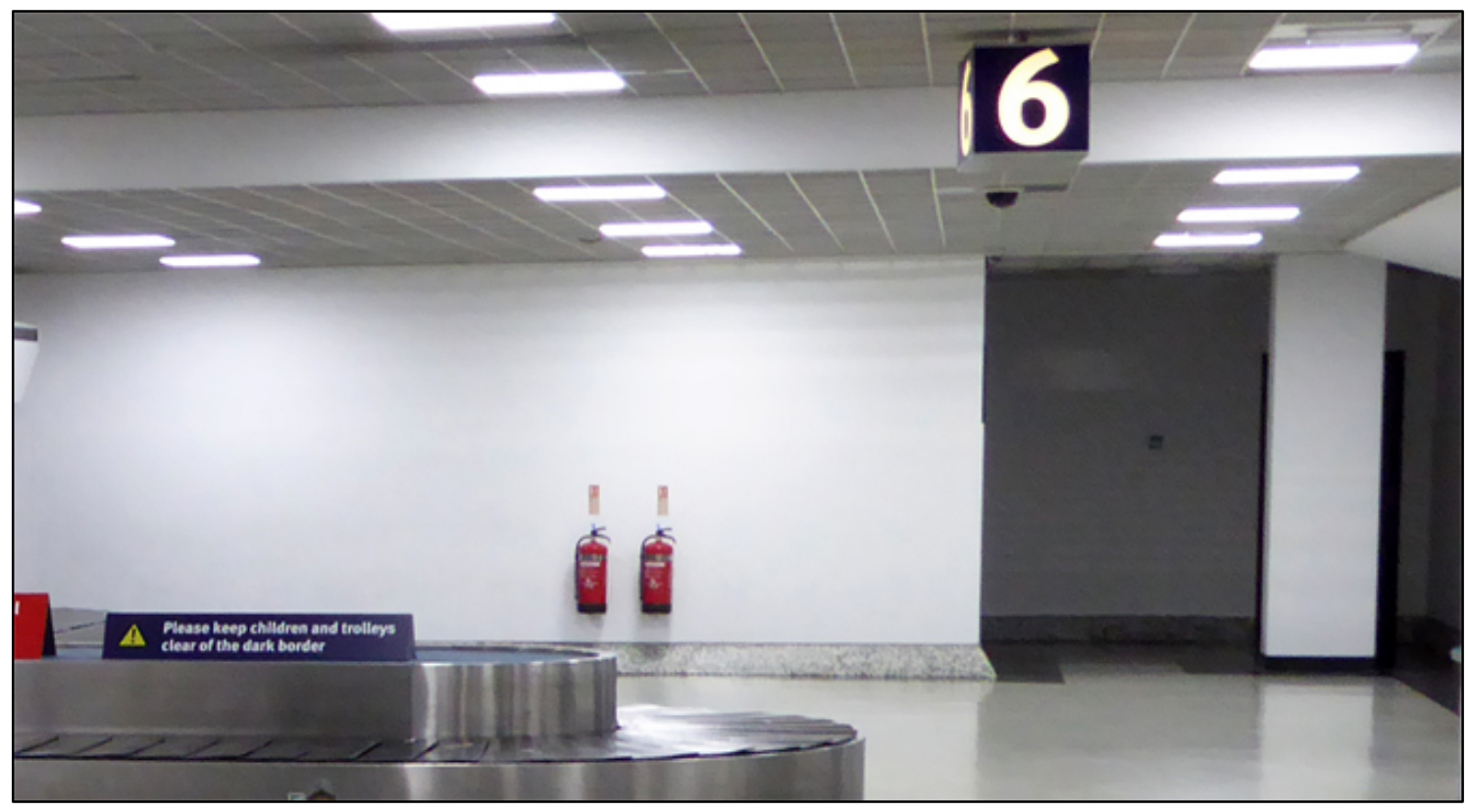

Figure 2 -Identifying signage example - in the image above, the numbered signage acts to confirm the location of carousel 6

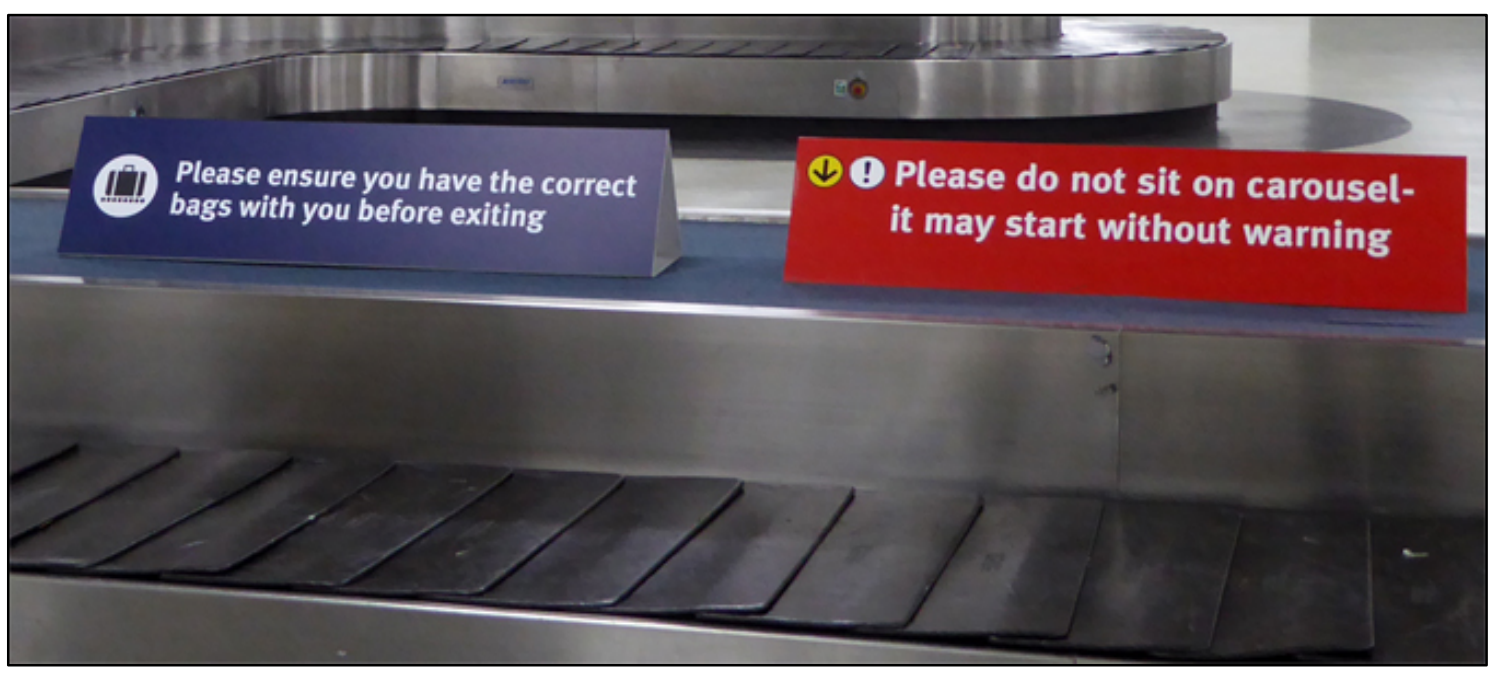

Figure 3 - Example of informational signage 
Wayfinding Signage Considerations in International Airports Symonds, $\mathrm{P}$.

Interdisciplinary Journal of Signage and Wayfinding; Volume 1; Issue 2

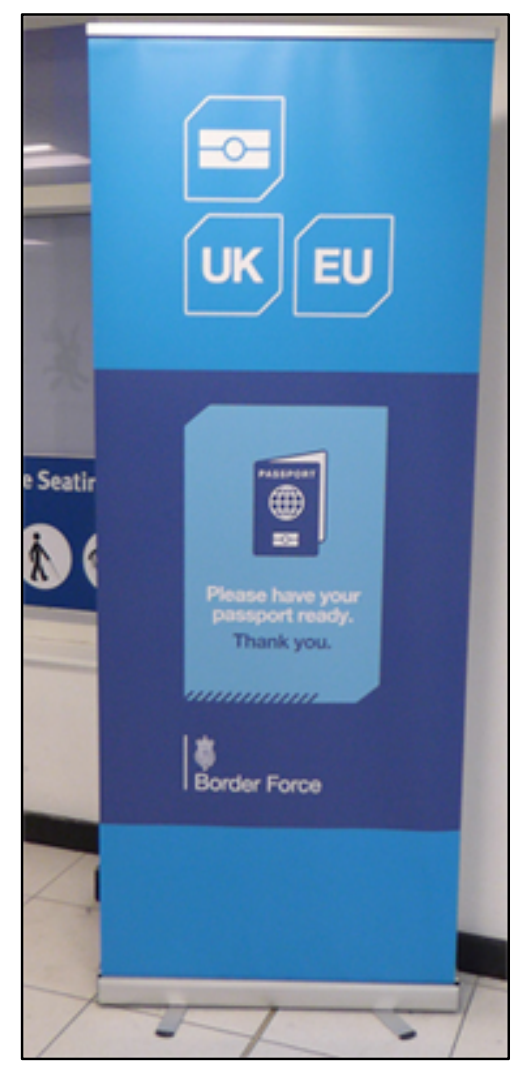

Figure 4 - Regulatory signage

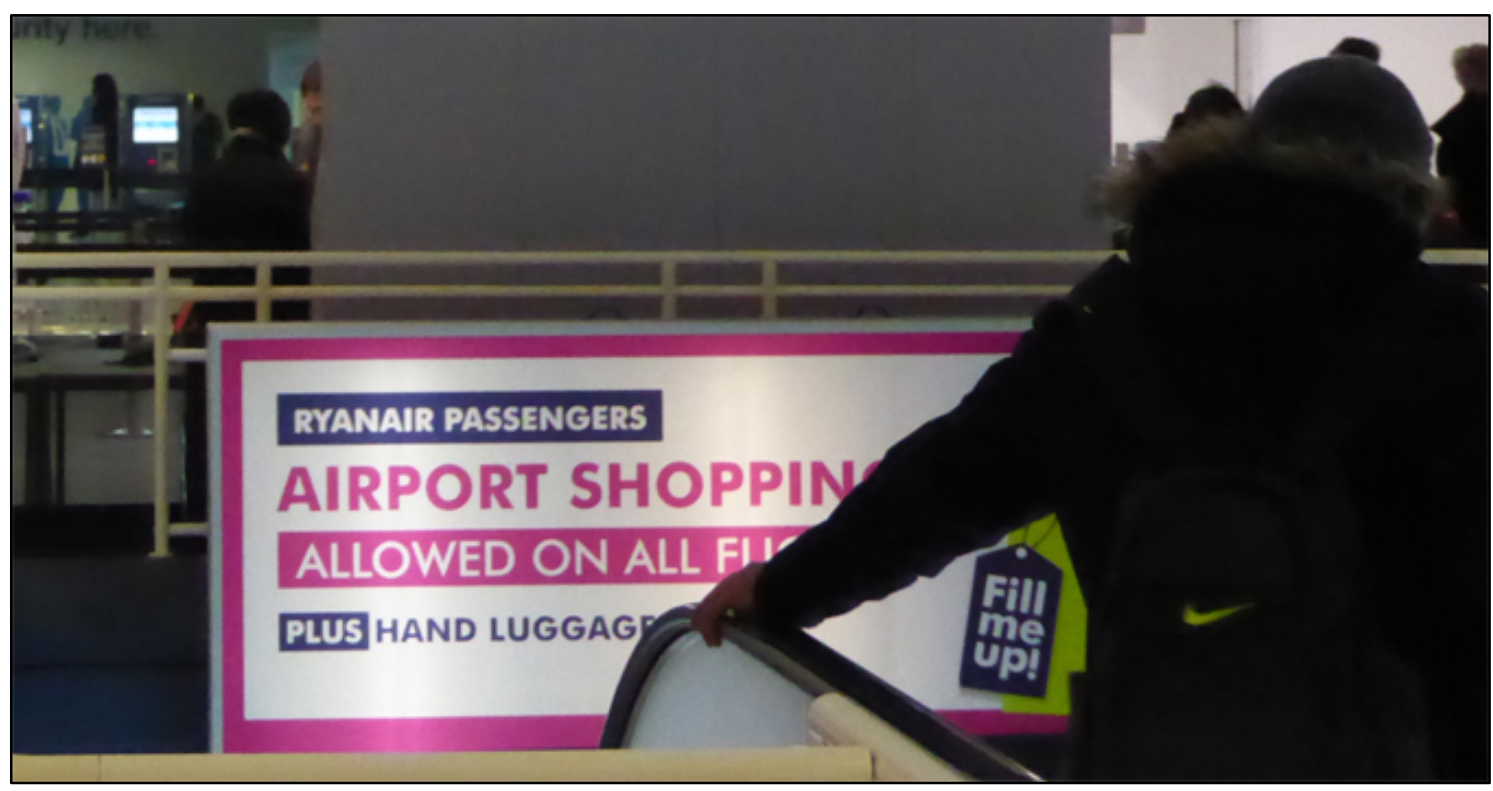

Figure 5 - Commercial signage example 
Wayfinding Signage Considerations in International Airports

Symonds, P.

Interdisciplinary Journal of Signage and Wayfinding; Volume 1; Issue 2

\section{Common Signage Problems in Airports Found and Solutions}

In the three airport audits, certain issues were experienced and in this section I will explain some of the most common issues seen and suggest examples of solutions.

\section{Multi Language}

Although not a problem as such in most American airports, consideration for the local language spoken in the country of the airport and the language spoken by a large number or even majority of passengers, creates a real dilemma for those planning the signage system and for the airport implementing the signage. Despite less than $12 \%$ of the residents of the Welsh capital Cardiff being able to speak Welsh (BBC, 2012), the airport is under immense pressure from the Welsh Assembly (government) to ensure that Welsh is included on all signage in the airport (Cardiff Airport, n. d.). Signage planning, in other words, can involve politically motivated decisions based on issues such as heritage.

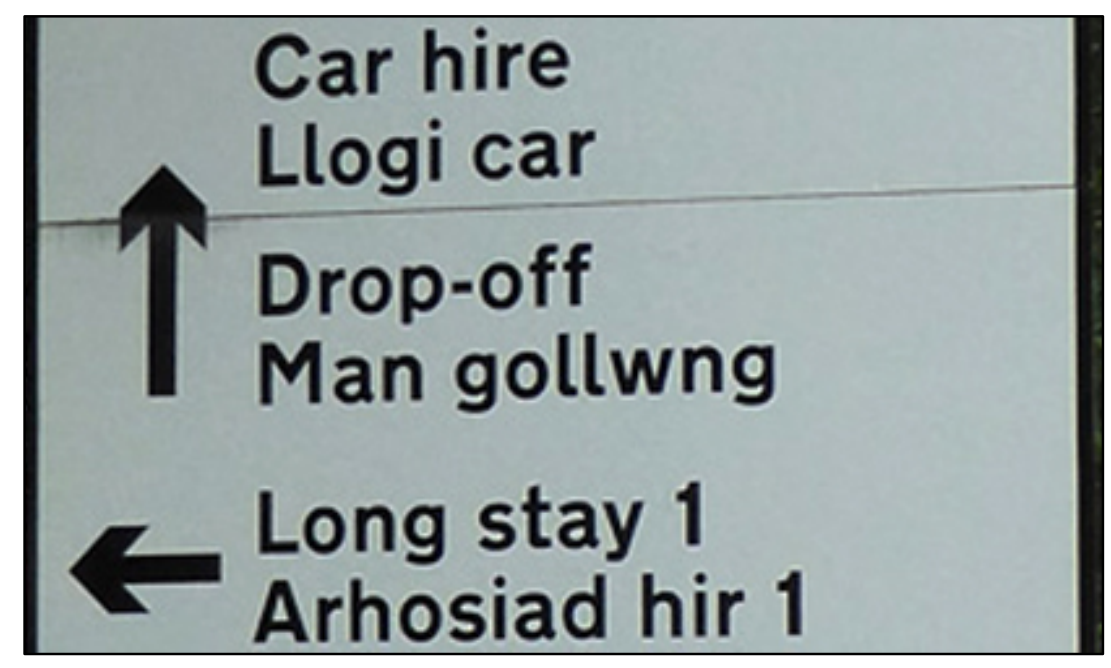

Figure 6 - Multi-lingual signs. An example of poor design.

There are a number of solutions for successfully including more than one language on signage. The use of colour coding, to make it clear to the passenger which text to focus on, can be particularly helpful, especially in the case where passengers are driving into an airport and have little time to make decisions. This was a particular problem in Cardiff Airport and certainly a reason for difficulties for passengers. Having one language in a different font size and separating each section of text with a line between each section was also suggested. Another option can be to make use, where possible, of icons that are globally recognised, rather than to use two languages. Toilet (restroom) signage can be created in this way to overcome linguistic issues. As Arthur and Passini (2002: 151) state, "the challenge of producing good signage is made more difficult by the fact that many people have reading problems that range from just poor reading habits up to not being able to read at all". Indeed, multi-language signage which does not differentiate the language by colour creates difficulties for readers. 
Wayfinding Signage Considerations in International Airports

Symonds, $\mathrm{P}$.

Interdisciplinary Journal of Signage and Wayfinding; Volume 1; Issue 2

\section{Inconsistency with a Font and Design Family}

Fewings (2001: 181) also makes an important point, stating that "signs should convey facts without ambiguity and at the time and place such facts are required. Signs should also direct, inform, control and identify, and it should be possible to distinguish between directional, identification and reassurance types of signs". These ambiguities that Fewings speaks of were a particular problem in two of the airports I audited and the reasons soon become clear. When talking with the airport management teams in the audit process, it become clear that a large number of signage suppliers end up being used for the airports. This results in a complete mismatch of signage in terms of a lack of standardised set of family fonts and design standards. As some airports develop, so do the number of suppliers and range of signage types. As signage experts, re-enforcing the need to try and bring all signage under one family and to create a standardised set of signs is needed. In order to try and create a more seamless signage system, involving as many of the key managers as possible, provides the greatest chance of ensuring that standardisation is brought to the airport as a whole.

Another problem experienced though that evolved from discussions with key personnel, is the understandable issue of costs and scope. A practical solution for developing a signage system for large airports and one preferred by those I talked with, was a multistage approach with specific parts of the airport planned for one at a time in respect of planning for signage. The cost of creating or replacing signage for all parts of an airport at once can be unrealistic. Hence, breaking down the process into manageable parts whilst first creating a standard plan that can be utilised airport wide, is suggested.

\section{Clustering}

Given the different forms of signage that exist in an airport setting (as mentioned earlier), "clustering" (Symonds, 2013) is an issue that needs to be avoided as various signs (signs that are sometimes put up by different departments within the same airport) begin to compete spatially with each other. The need to make airports profitable, particularly in countries such as the UK where airports are not state controlled, can be seen in some airports to result in commercial signage sometimes over-powering and effectively hiding or blocking directional wayfinding signage. The solution to avoid clustering is to create specific areas for each signage type. Advertising signage, for example, should not be placed alongside directional signage. Clear grouped areas for signage should be planned and site-lines for directional signage also need to be maintained. 
Wayfinding Signage Considerations in International Airports Symonds, $\mathrm{P}$.

Interdisciplinary Journal of Signage and Wayfinding; Volume 1; Issue 2

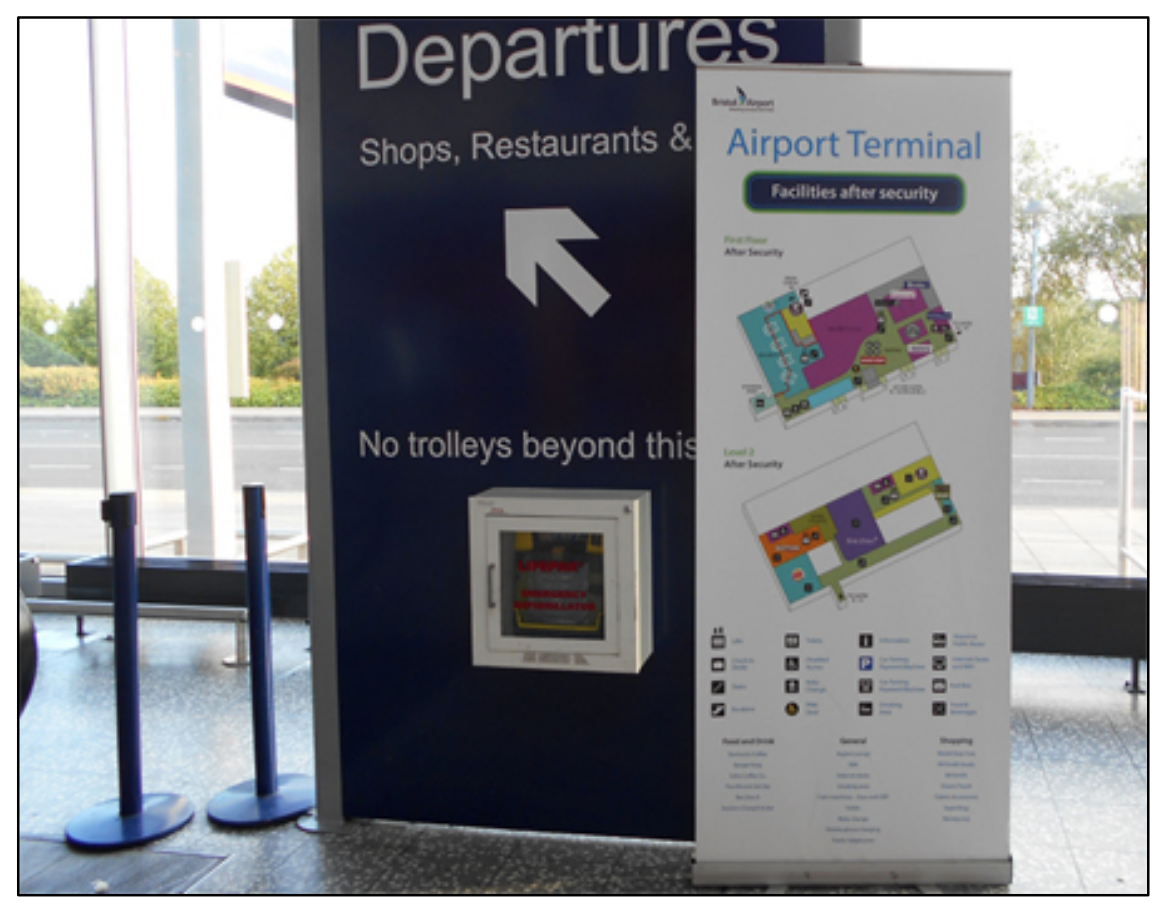

Figure 7 - Competing signage

\section{Design Inconsistencies and Errors}

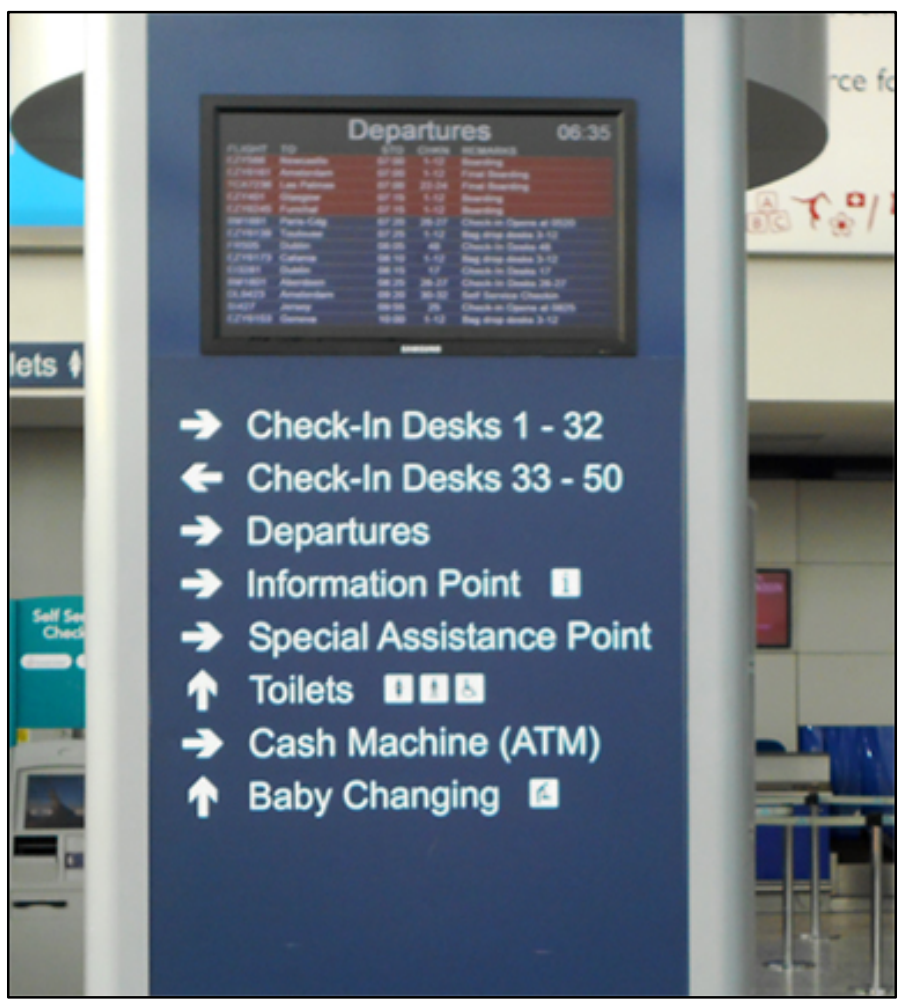

Figure 8 - Common signage errors 
Wayfinding Signage Considerations in International Airports

Symonds, P.

Interdisciplinary Journal of Signage and Wayfinding; Volume 1; Issue 2

Auditing the three airports, inconsistencies in basic signage design standards and conventions were noticed in every airport. Such issues are common and the one sign above in Figure 8 highlights three obvious problems. Firstly, it shows a lack of consideration to the natural groups of texts in the sign. "Toilets" (Restrooms in American) should, for example, be grouped above or below "Baby Changing". Locations that are logically connected should be grouped in signage to make it easier for users to cognitively use signage more easily and naturally. Secondly, for best practice, arrows should always point away from text and towards the direction of the item they are pointing to, making it easier for users to distinguish the direction they need to take, rather than text pointing into text. Thirdly, inconsistency exists in respect of language with a mix of British English (such as "toilets" and "cash machine") and American English ("ATM"). Although such points might seem somewhat pedantic, such issues, when magnified by thousands of signs in a large airport, mean that wayfinding becomes more problematic.

\section{Understanding the User Types}

Not fully understanding the needs of all user types for a given airport is an issue that can be avoided relatively easily and yet proved to be problematic. What became apparent was that not all users will take the same routes in the way that one might at first expect. One particular example stands out from my interviews in my own $\mathrm{PhD}$ research on wayfinding. A disabled traveller, whom I will refer to as Mary for reasons of anonymity (in line with research ethics guidelines for the $\mathrm{PhD}$ ), for example, rather than looking for the check-in area when arriving at an airport terminal, normally needs to find the "Special Assistance".

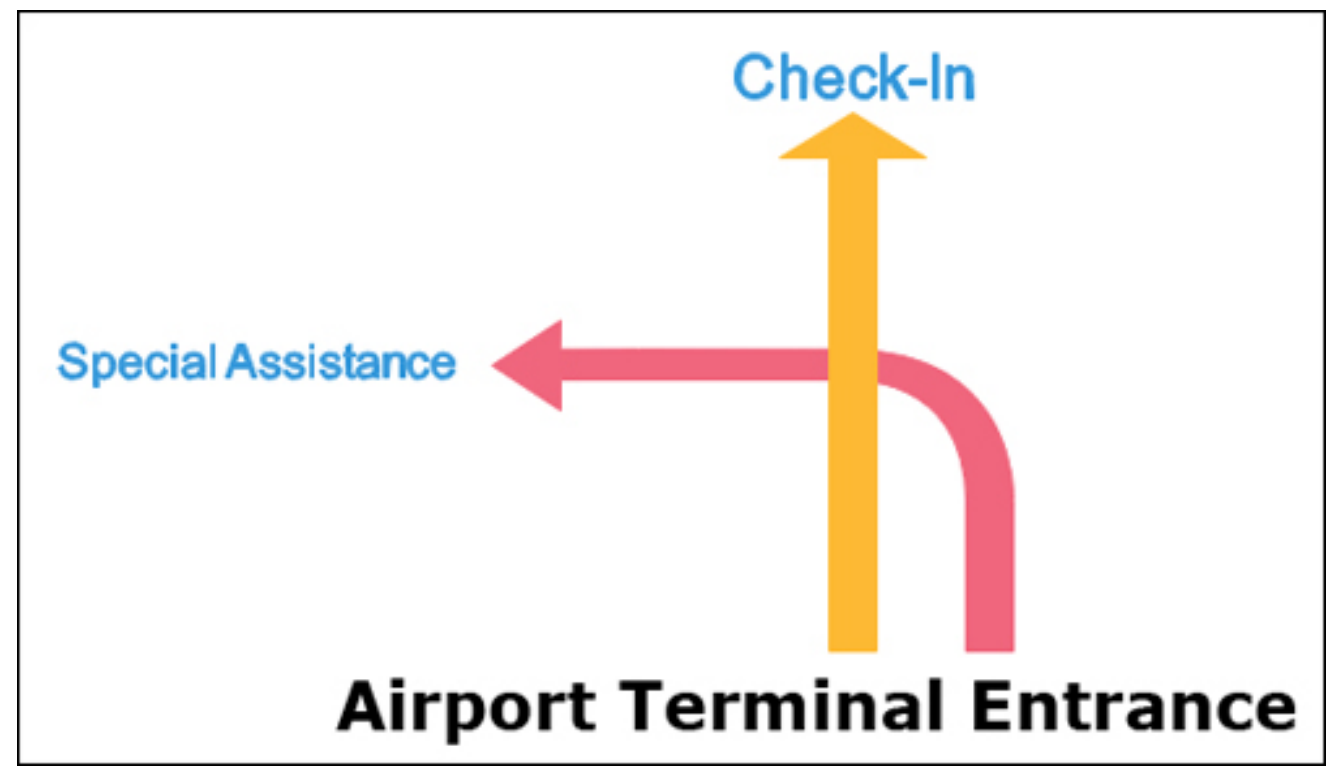

Figure 9 - Example route that may be needed for disabled passengers with check-in the second rather than first destination when entering a terminal.

While this is not an issue with the design of the signs themselves, the issue that exists is 
Wayfinding Signage Considerations in International Airports

Symonds, $\mathrm{P}$.

Interdisciplinary Journal of Signage and Wayfinding; Volume 1; Issue 2

in being able to fully understand the routes and paths that need to be signposted in the first place. From the experiences of spending much time in three airport terminals and dressed in shirt and tie and with an airport visitor I.D around my neck, what was both surprising and interesting was the frequency with which passengers would approach me to ask the directions. Literally every minute or so, I would be asked for directions and, quite often, it was the same gate that passengers were having problems to identify the directions for. On further investigation, by looking for the directions myself, it soon became clear that one particular gate was an abyss in respect of the ability to find any directional information for that specific gate. The lesson here, for signage companies looking to create the best possible signage system in such an environment, is to spend even a very small budget just to gather some feedback from the very users who are likely to use the signage system in question. Moreover, the most knowledgeable people from the experiences of doing the audits proved to be, apart from the passengers, the front line service staff who get asked the same questions day in day out, including regards to specific locations. Making assumptions when designing a signage system often proves to be the reason for many poorly designed and ineffectively systems.

The range of user types also extends to division between those who are "familiar" and "unfamiliar" (Kellaris and Machleit, 2016: 5; Prestopnik and Roskos-Ewoldsen, 2000: 178). In addition to various levels of familiarity, effective signage in airports needs to accommodate a number of factors and these include a range of "ages", "motivations" and "internal states" as represented by Kellaris and Machleit (2016: 5) in their "Conceptual Framework for Signage Communication". By "internal states", Kellaris and Machleit (2016) and also Symonds et al (2017) refer to the emotional states and embodied effects that can affect the way in which a user will interpret signage and how the wayfinding takes place. Indeed, herein lies the importance of signage in the form of "confirmational signage", signs that provide confirmation and put a user's mind at rest. In airports long walks to a departure gate, even when the route is a direct one and users cannot take a wrong turn, they can still benefit from signage placed every so often to confirm the distance in terms of time or physical distance to the destination.

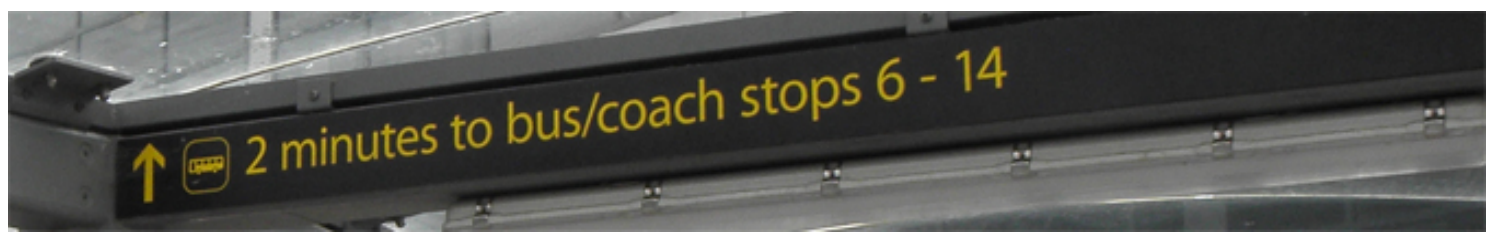

Figure 10 - Making use of confirmational signage

Wayfinding as an emotional experience can be increasingly so for those who are in need of "Special Assistance". As Small et al (2012: 942) posit, the "bodily experience of tourism is likely to be very different for the able bodied tourist and the tourist who is disabled". Signage can be used as an effective tool in order to help alleviate the cognitive stresses that such travellers experience, through the use of confirmational signs for providing information that acts as a source of comfort. Figure 11, below, shows another example of signage used to relieve passengers anxiety, in this case for those who are in 
Wayfinding Signage Considerations in International Airports

Symonds, $\mathrm{P}$.

Interdisciplinary Journal of Signage and Wayfinding; Volume 1; Issue 2

need of special assistance, and who can often find using airports more traumatic than other passengers.

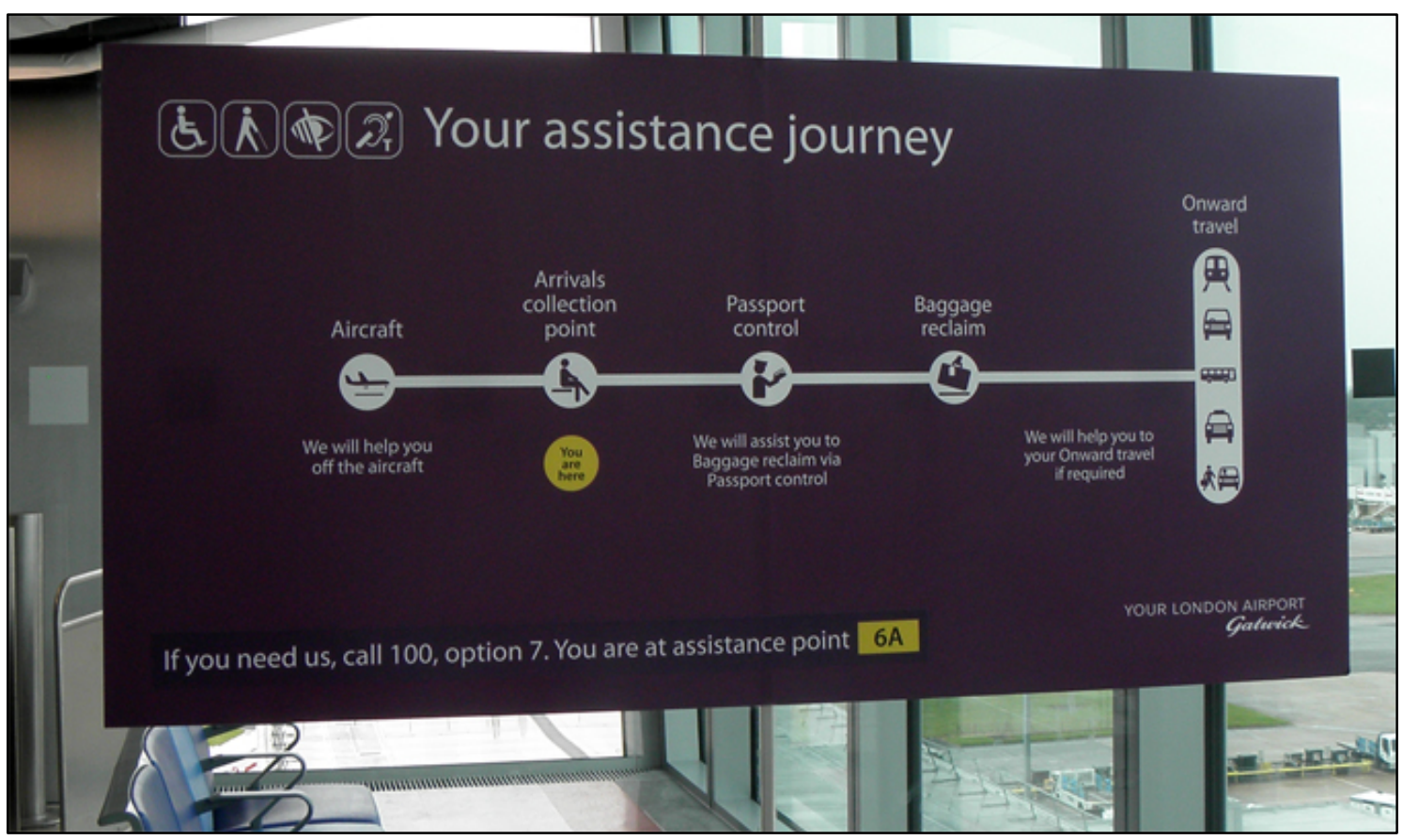

Figure 11 - Using signage to re-assure users about the route.

What Kellaris and Machleit (2016: 5) refer to as "motivational predispositions", meaning the "extent to which people enjoy and regularly engage in the process of thinking" is an especially important consideration in locations in which signage is being used by a high percentage of holidaymakers or tourists. In certain situations, such as when we travel for vacation purposes, we can be in a heightened emotional state (we are excited for example) and we can thus become what Culler (1988: 1) rather interestingly describes as "droves, herds, swarms or flocks; they are as mindless and docile as sheep but as annoying as a plague of insects when they descend upon a spot they have discovered". Although a somewhat cynical way of explaining the habits of tourist, Culler makes an important point in that on vacation, and in other situations that can be emotive, there is a need to ensure that the signage system that is designed for such users, needs to factor in the difference in moods that we may experience in non-quotidian situations. In an airport, for example, the normally fast thinking and ever alert business wo/man, might be a passive and somewhat relaxed and unthinking traveller, as they relax, enjoy a drink in the airport bar and focus on their holiday. This is a journey, in other words, for unwinding and to be an unthinking individual and to enjoy being a sheep. One solution, in recent years, to cater for all emotive states, ages and abilities, has been a drive towards less but very large, high and bold signage, in the UK. 
Wayfinding Signage Considerations in International Airports

Symonds, $\mathrm{P}$.

Interdisciplinary Journal of Signage and Wayfinding; Volume 1; Issue 2

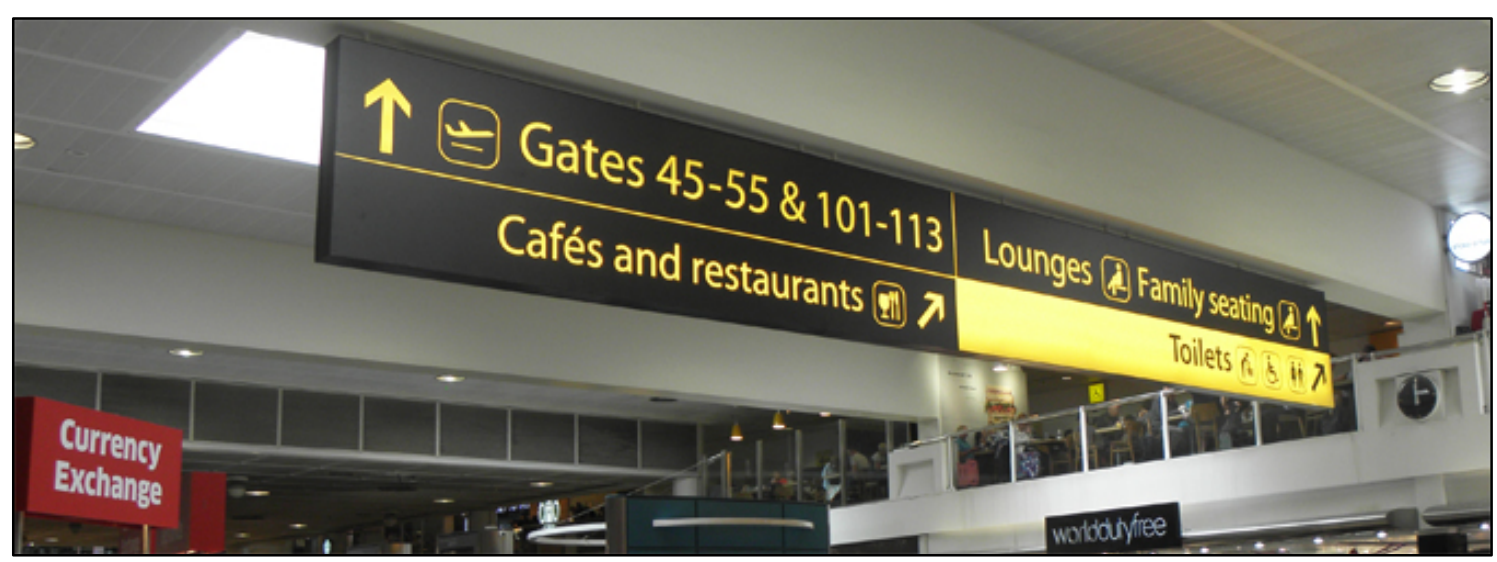

Figure 12 - Highly placed and very large unmissable signage.

\section{Understanding the Embodied Wayfinding Experience and Signage Systems Design}

Understanding wayfinding as a fully embodied experience also helps to shape the understanding of how signage systems can best be developed. In Figure 13 below, a model for wayfinding as an embodied experience is presented, taken from Symonds et al (2017: 4.1). Originally inspired by the model created by Lo Iacono and Brown (2016) to present intangible cultural heritage, the model presents the concept of wayfinding as a fully embodied experience that includes the cognitive and sociocultural.

Signage is presented under the heading "environment \& artefacts". The diagram is useful for expressing the places and socially active environments in which signage needs to be effective. By understanding wayfinding as an embodied activity rather than a cognitive only one, many of the mistakes that can occur in signage systems design can be avoided. Signage design that ignored the emotions, for example, (as earlier discussed) that inevitably exist when we wayfind and as also discussed by Kellaris and Machleit (2016) need to be factored into signage planning. There is the opportunity to avoid some of the mistakes that can otherwise exist in wayfinding research. 
Wayfinding Signage Considerations in International Airports

Symonds, P.

Interdisciplinary Journal of Signage and Wayfinding; Volume 1; Issue 2

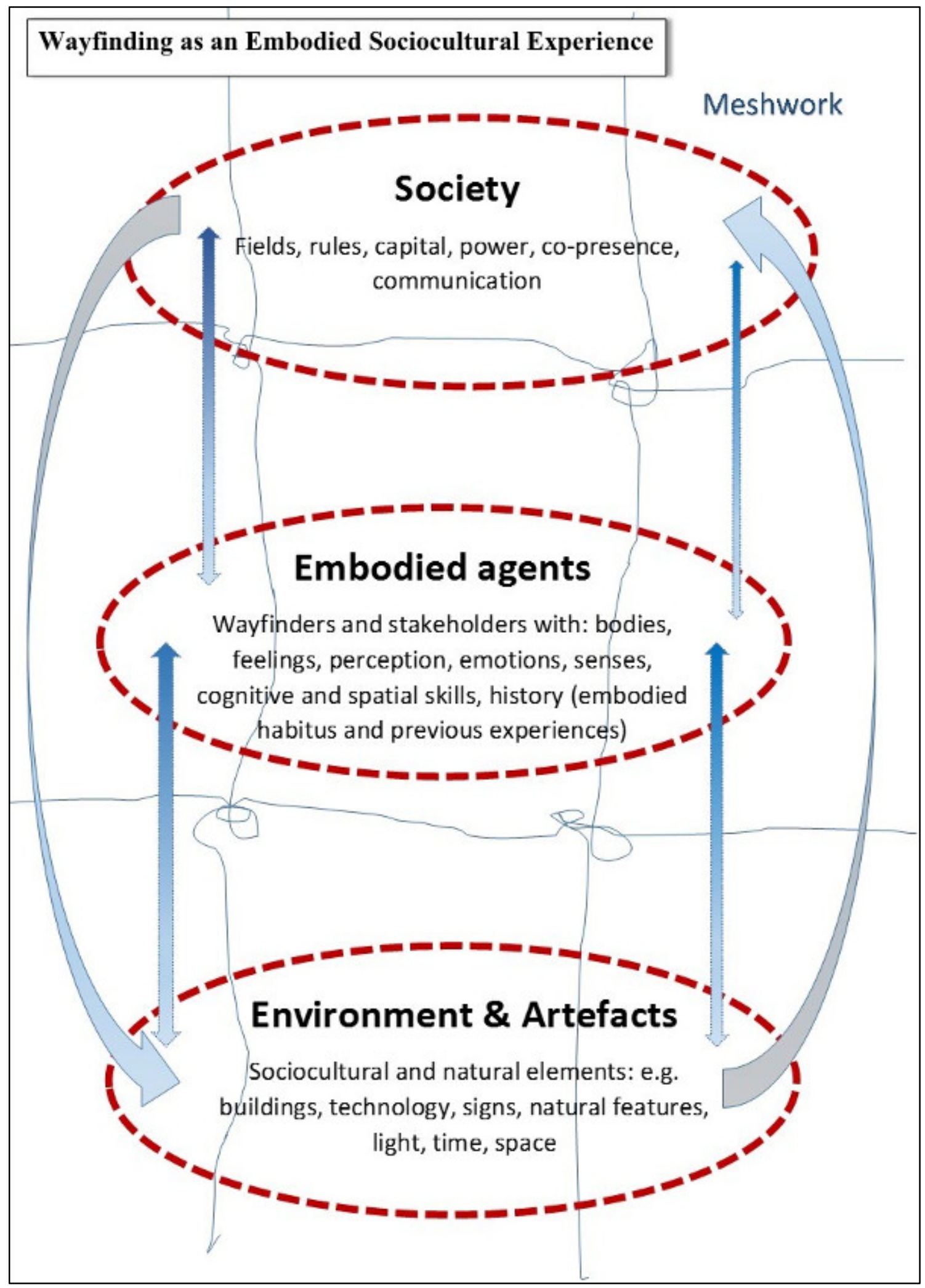

Figure 13 - Taken from Symonds et al (2017: par. 4.1) where a full explanation of the diagram can also be found. 
Wayfinding Signage Considerations in International Airports

Symonds, $\mathrm{P}$.

Interdisciplinary Journal of Signage and Wayfinding; Volume 1; Issue 2

To provide an example in airports, floor signage in the form of coloured lines that can be followed (Vilar et al, 2012: 4), such as to the train station serving an airport, can be extremely effective. Tested by virtual means as many wayfinding studies have tended to do (see Cubukcu, 2003; Emo, 2012 for example), the results would likely be that the floor lines work very effectively.

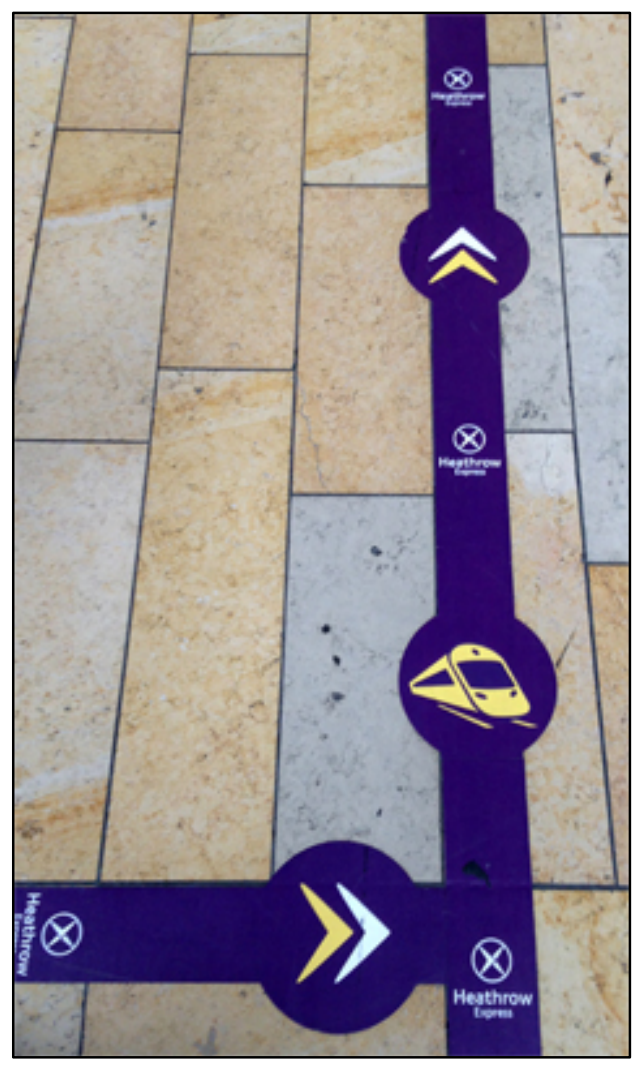

Figure 14 - Floor signage

When applied to an embodied wayfinding test, the results though can prove to be very different! The presence of numerous other bodies, for example, using the same physical spaces means that these lines can become hard to see, and also difficult to follow because other people block the way. Moreover, during the perambulatory process, the wear and tear of shoes and heels on the floor lines can quickly cause the lines to become eroded. In analysing wayfinding as an embodied process, greater understanding can be brought to signage design with the cognitive and corporeal seen as one under the term embodiment.

In real-world ${ }^{1}$ wayfinding, certain features and thought-processes in signage design have long existed that factor in sociocultural needs. As shown in the image below in Figure 15 for example, from Gatwick Airport (London), consideration throughout the airport is given to height and signage placement. Placed at face height, such signage may be impossible to see in crowded environments. In order to overcome the resulting issue from placing signs so high, consideration has then been given to ensuring that the signs use

\footnotetext{
1 "Real world" is used to refer to the lived physical world in which we live, as opposed to the virtual world.
} 
Wayfinding Signage Considerations in International Airports

Symonds, P.

Interdisciplinary Journal of Signage and Wayfinding; Volume 1; Issue 2

very large fonts and with the text written on contrasting colours (in this case yellow on black). Consideration is also given throughout the airport to background lighting,

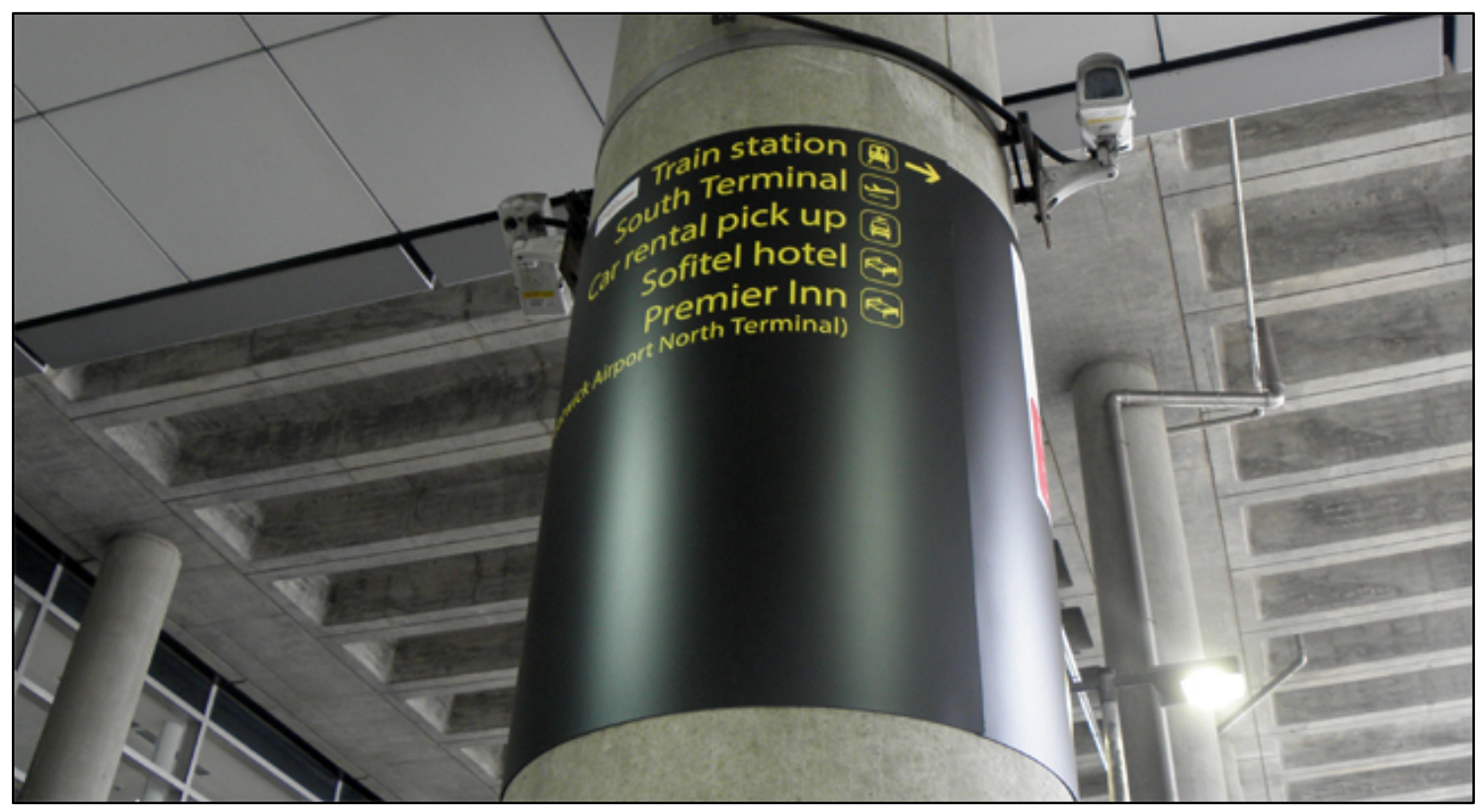

Figure 15 - Very high signage.

\section{Use of Colour Differentiation and for Signage Grouping}

Another useful technique used in the airports audited, is that of using colour for setting standards for signage types. Any signs relating to emergencies, for example, were always green in the three airports studied (see Figure 16 below).

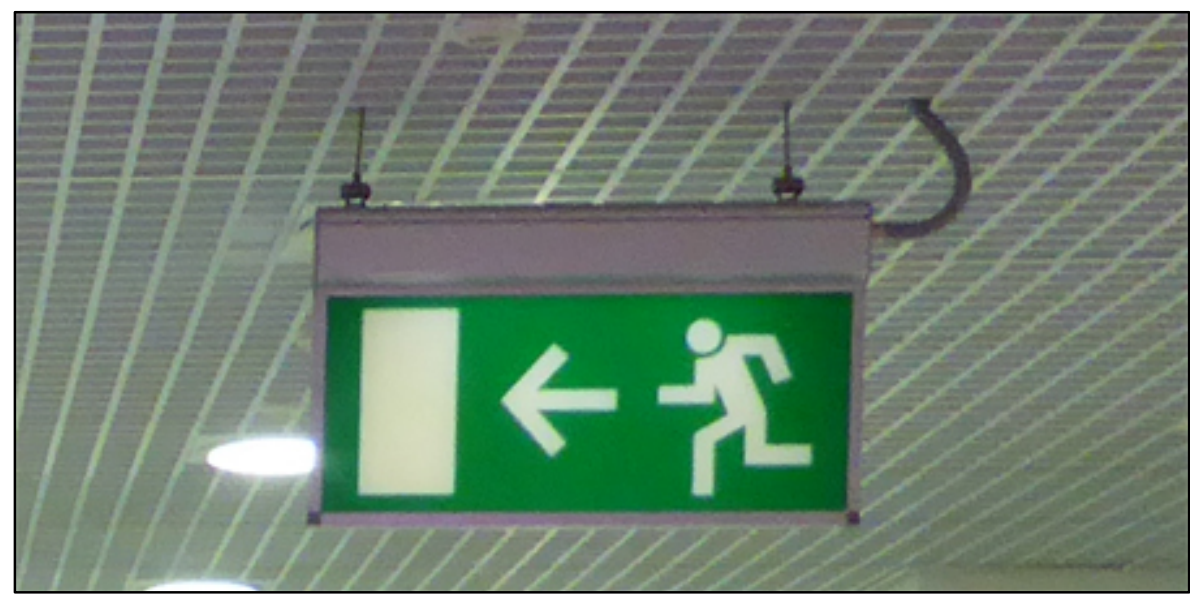

Figure 16 - Emergency signage

Likewise, the colour yellow is used throughout the airport to represent toilets (restrooms) and is thus used to re-inforce signage in the form of text and symbols. Indeed, the use of 
Wayfinding Signage Considerations in International Airports

Symonds, $\mathrm{P}$.

Interdisciplinary Journal of Signage and Wayfinding; Volume 1; Issue 2

colour is common as a way of re-enforcing signage. Read (2003: 235), in talking of child care environments, explains how colour can be used to guide people to their destination, whilst Sheehan et al (2006: 279), explain how those with special needs, such as dementia sufferers, have also been shown to be able to find their way easier, when colour is also used in partnership with signage as a tool.

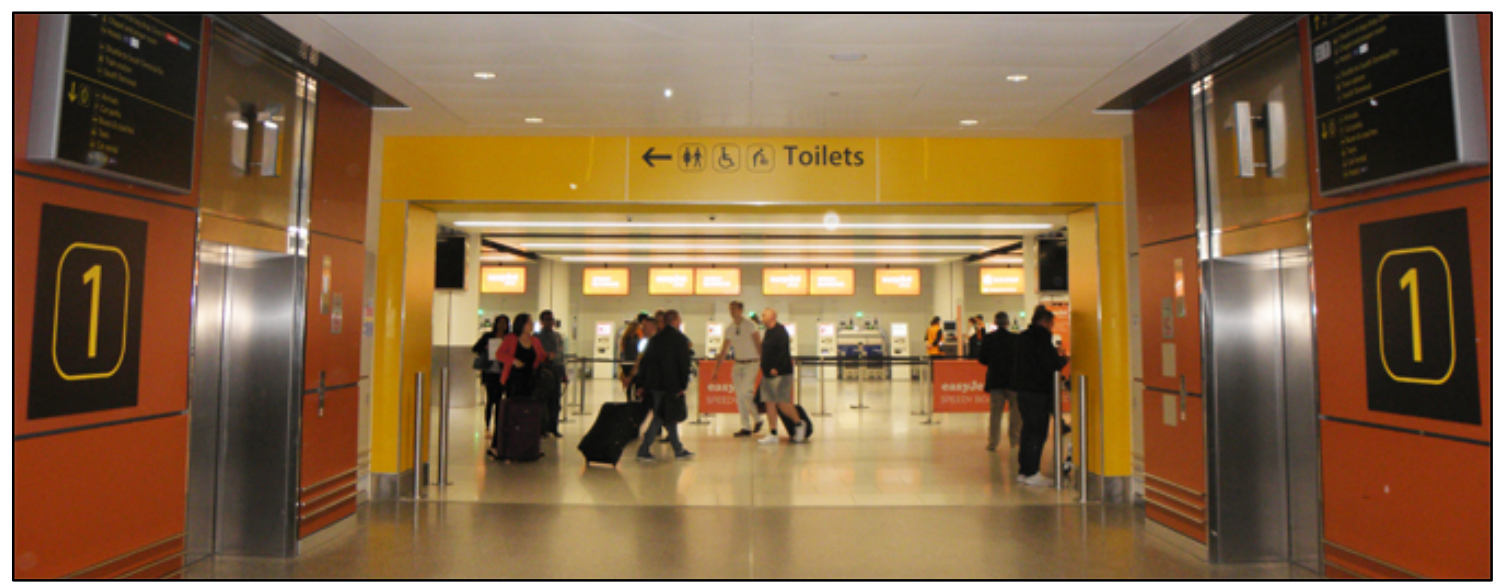

Figure 17 - Gatwick Airport, London, and the use of colour Differentiation.

\section{Temporary Signage}

Another issue that became very apparent in all three airports was the extent to which temporary signage can be an issue. In very large international airports such as Gatwick Airport, some part of the airport is always being re-developed or changed, and signage and wayfinding is very often central to this process. In this respect, the point that Ingold (2011: 148-149) makes that wayfinding (and wayfaring) are like life itself, resonates here. Wayfinding is never a precise science, in that two people will never ever take precisely the same route using the exact same movements and signage needs ultimately to accommodate life-like movements, i.e. accommodate human factors. Like the heuristic and life-like movements for which signage must be developed for, the signage systems and spaces themselves also evolve and thus embody change and movement much like the people these spaces and signs work for.

In airports, temporary signage can be needed for a variety of reasons, such as because of terminal re-design, the change in airlines and their check-in desk location, expansion, or simply for repair work. Repairing wayfinding signage in the largest of airports, it should be remembered, is in an ongoing task. In one of the airports audited, the temporary signage was confusing and, on briefly observing passengers, it was clear that they were getting confused in terms of directions. There are two key issues when creating temporary signage in airports that I experienced. Firstly, the temporary signage did not match the font family and design specifications of the main signage system. Whilst this is understandable in that it is only temporary, I would argue that larger airports should be able to brand temporary signage and maintain a signage family (same fonts, designs and colours etc). Secondly, temporary signage, from my experience from these audits and 
Wayfinding Signage Considerations in International Airports

Symonds, $\mathrm{P}$.

Interdisciplinary Journal of Signage and Wayfinding; Volume 1; Issue 2

from other audits, so often sends people in the wrong direction and unnecessarily creates a bad experience for passengers. Too little effort, in other words, is often allocated to temporary signage installation and design, and in large airports, where changes are continually being made, this can generate negative user experience (UX).

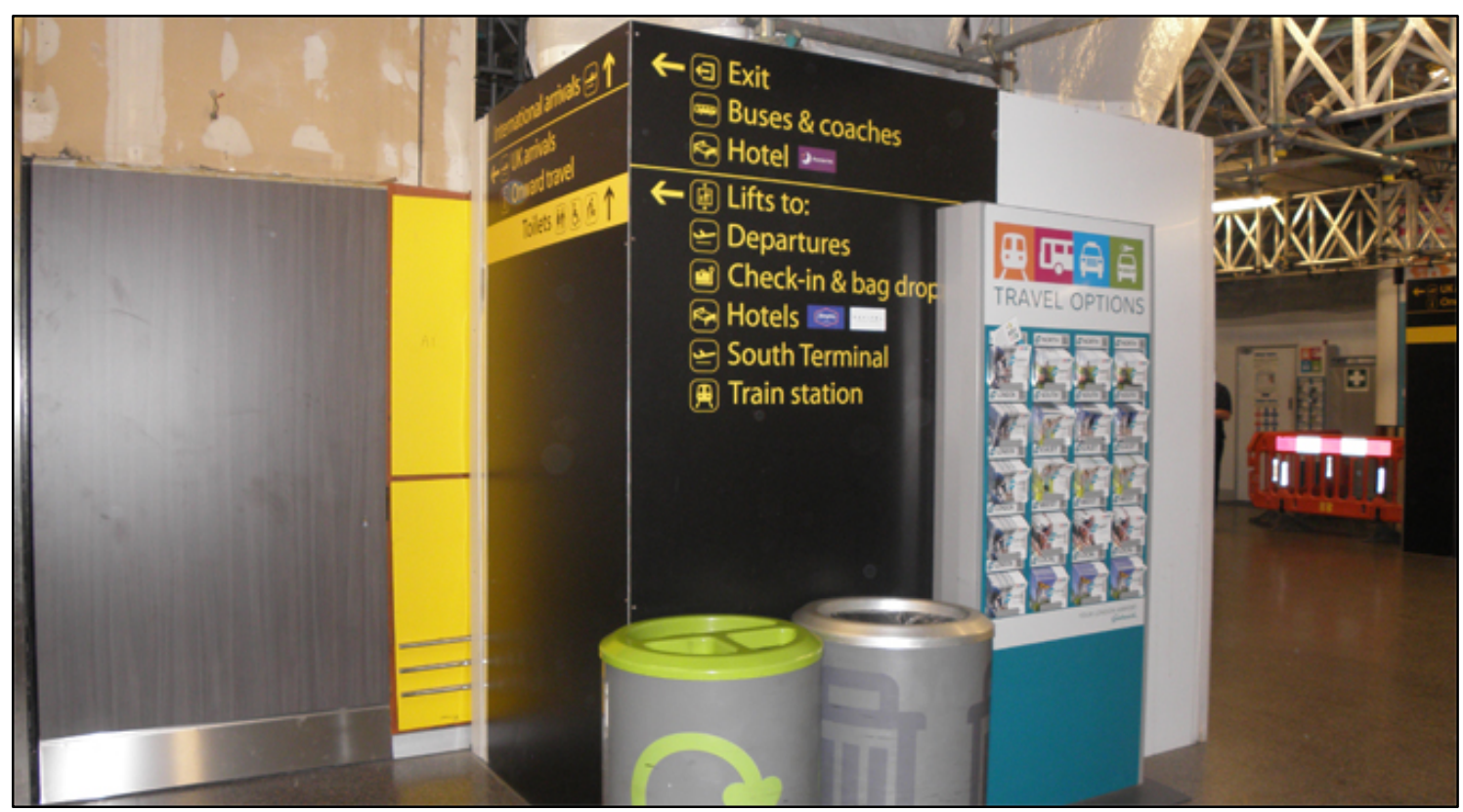

Figure 18 - Gatwick have a significant wayfinding budget and do go to great lengths also to present branded temporary signage.

\section{Other Signage Considerations}

Free-standing signage wrongly positioned - The key to managing a large signage system in a large airport is to create a wayfinding audit list and to do regular checks, i.e. weekly or monthly. In doing such checks, one problem that can easily be corrected and that occurs, such as because cleaners have moved them to clean underneath them, is free standing signage. In the audit, several signs in Birmingham Airport, UK, were facing the wrong way and would send passengers in the wrong direction. 
Wayfinding Signage Considerations in International Airports

Symonds, P.

Interdisciplinary Journal of Signage and Wayfinding; Volume 1; Issue 2

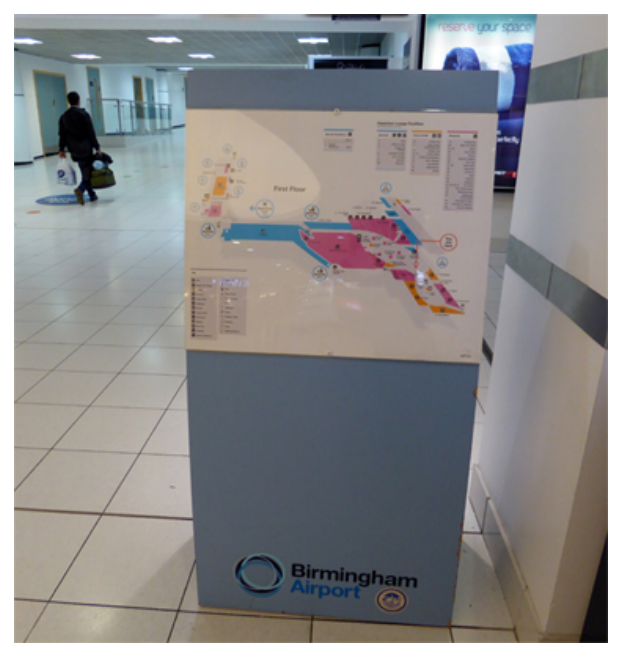

Figure 19 - Free-standing signage facing the wrong way.

In highlighting many of the problems found, it is worth also noting that many things are done very well in the airports audited! The correct use, for example, of signage hierarchy was used in all three airports. By signage hierarchy this refers to the need to only include direct needs on signage. On arriving into an airport, for example, it is not necessary to sign for specific departure gates because it is too early in the decision making process. In such a case, directing users to the correct terminal (if there is more than one terminal) or towards the correct parking area is necessary. In all airports studied, signage system hierarchies were very well developed.

\section{Conclusions and Recommendations}

In this paper, I have presented a range of findings and observations from three wayfinding audits that I did in the UK in the last year. One of the key points to be made is that wayfinding signage systems in very large locations (such as in an international airport) need to be seen as organic systems and proper documentation and continual re-auditing of the signage system needs to exist. Furthermore, where possible, the signage system should use a signage family (i.e. fonts, styles, colours) and a seamless approach should be taken to ensuring that all areas of the airport integrate effectively.

It was also explained that most wayfinding work on signage systems in airports tends to be adapted rather than newly created. The reality of many airports is that they start off small and develop according to route development, resulting increase in passenger numbers and because of other factors. In order to try and maintain a standard structure in a large airport, despite the influence of a number of managers in different areas and aspect of a large airport, the key is to having an airport wayfinding signage plan where possible.

Rather than only seeing wayfinding as a cognitive practice, by seeing and analysing wayfinding as a fully embodied process, we can understand how multiple bodies, using the same signage system, can complement and aggravate each other's experiential use of the signage system. Airport signage systems need to consider human factors also, such as how signage may move because of quite simple issues such as because of cleaners moving 
Wayfinding Signage Considerations in International Airports

Symonds, $\mathrm{P}$.

Interdisciplinary Journal of Signage and Wayfinding; Volume 1; Issue 2

free -standing signage. Many airports have no system in place to check such easy to fix issues and have no standard procedure in place to do signage checks on a regular basis. 
Wayfinding Signage Considerations in International Airports

Symonds, P.

Interdisciplinary Journal of Signage and Wayfinding; Volume 1; Issue 2

\section{References}

ACI. (2016). ACI releases preliminary world airport traffic rankings. Retrieved February 23, 2017, from http://www.aci.aero/News/Releases/MostRecent/2016/04/04/ACI-releases-preliminary-world-airport-traffic-rankings-

Arthur, P., \& Passini, R. (2002). Wayfinding: people, signs, and architecture. Oakville, Ont.: Focus Strategic Communications.

BBC News. (2012, December 11). Census 2011: Number of Welsh speakers falling. BBC News. Retrieved from http://www.bbc.co.uk/news/uk-wales-20677528 on 22nd May 2017.

Bourdieu, P. (1977). Outline of a Theory of Practice (Vol. 16). Cambridge University Press.

Cardiff Airport. (n.d.). Welsh language policy. Retrieved February 27, 2017, from https://www.cardiff-airport.com/welsh-language-policy/

Cubukcu, E. (2003). Investigating wayfinding using virtual environments. The Ohio State University.

Culler, J. D. (1988). Framing the sign: Criticism and its institutions. Basil Blackwell Oxford.

Emo, B. (2012). Wayfinding in real cities: Experiments at street corners. In Spatial Cognition VIII (pp. 461-477). Springer. Retrieved from http://link.springer.com/chapter/10.1007/978-3-642-32732-2_30

Fewings, R. (2001). Wayfinding and airport terminal design. Journal of Navigation, 54(2), 177-184.

Gottdiener, M. (2000). Life in the Air: Surviving the New Culture of Air Travel. Lanham, Md: Rowman \& Littlefield Publishers.

Ingold, T. (2011). Being alive: essays on movement, knowledge and description. London; New York: Routledge.

Kellaris, J. J., \& Machleit, K. A. (2016). Signage as Marketing Communication: A Conceptual Model and Research Propositions. Interdisciplinary Journal of Signage and Wayfinding, l(1).

Lo Iacono, V. L., \& Brown, D. H. (2016). Beyond Binarism: Exploring a Model of Living Cultural Heritage for Dance. Dance Research, 34(1), 84-105. [doi:10.3366/drs.2016.0147]

Lo Iacono, V., Symonds, P., \& Brown, D. H. K. (2016). Skype as a Tool for Qualitative Research Interviews. Sociological Research Online, $21(2), 12$. https://doi.org/10.5153/sro.3952

Lynch, K. (1960). The image of the city. Cambridge, Mass.: MIT Press.

Prestopnik, J. L., \& Roskos-Ewoldsen, B. (2000). The Relations among wayfinding strategy use, sense of direction, sex, familiarity, and wayfinding ability. Journal of Environmental Psychology, 20(2), 177-191. https://doi.org/10.1006/jevp.1999.0160

Read, M. A. (2003). Use of color in child care environments: Application of color for wayfinding and space definition in Alabama child care environments. Early Childhood Education Journal, 30(4), 233-239.

Sheehan, B., Burton, E., \& Mitchell, L. (2006). Outdoor wayfinding in dementia. Dementia, 5(2), 271-281. 
Wayfinding Signage Considerations in International Airports

Symonds, $\mathrm{P}$.

Interdisciplinary Journal of Signage and Wayfinding; Volume 1; Issue 2

Silverman, D. (2013). Doing qualitative research: A practical handbook. SAGE Publications Limited.

Small, J., Darcy, S., \& Packer, T. (2012). The embodied tourist experiences of people with vision impairment: Management implications beyond the visual gaze.

Tourism Management, 33(4), 941-950. https://doi.org/10.1016/j.tourman.2011.09.015

Symonds, P., Brown, D. H. K., \& Lo Iacono, V. (2017). Exploring an Absent Presence: Wayfinding as an Embodied Sociocultural Experience. Sociological Research Online, 22(1), 5. https://doi.org/10.5153/sro.4185

Symonds, P. (2013). Clustering and Signage in Wayfinding. Retrieved from http://www.travelwayfinding.com/clustering-and-signage/

Vilar, E., Rebelo, F., \& Noriega, P. (2012). Indoor human wayfinding performance using vertical and horizontal signage in virtual reality. Human Factors and Ergonomics in Manufacturing \& Service Industries, n/a-n/a. https://doi.org/10.1002/hfm.20503

\section{Funding}

No bursaries or any type of funding was received for this study.

\section{Images Used}

All images used are from Paul Symonds

\section{About the Author}

Paul Symonds is completing a $\mathrm{PhD}$ in wayfinding and runs www.symondsresearch.com. He presently lives in Cardiff, UK, but has previously lived in USA, Korea, Spain and Ireland. Paul's research interests are wayfinding, research methods, embodiment and sociology. 